\title{
Gender-Specific Online Content Is Important and Timely for Women Receiving Treatment for Substance Use Disorders
}

\author{
Carolyn A. Day, PhD and Natalie White, BappSc(OT), MPH
}

$\mathbf{S}$ UGARMAN ET AL.S' RECENT STUDY MAKES an important advancement in the provision of gender-specific interventions for women seeking drug and alcohol treatment. ${ }^{1}$ This study is especially important at this time when the world is gripped by the COVID-19 pandemic. Substance use and relapse are likely to be high during this period, but many drug and alcohol services have been, or may be, forced to switch to online service delivery or telehealth where the evidence base, although increasing, is less robust, especially for very marginalized populations. ${ }^{2}$ The problem is further compounded by the mandated isolation measures currently in place in many countries. Such measures may increase the risk of family or intimate partner violence, a problem already prevalent among women with substance use histories. ${ }^{3}$ Together these issues place further pressure on genderspecific substance use services at a time when service provision and resources are limited.

This recent study by Sugarman et al. highlights the acceptability and feasibility of providing web-based genderspecific treatment within a mixed-gender treatment setting. ${ }^{1}$ Numerous studies have identified that gender-specific treatment models may be superior for women with substance use disorders, yet a range of practical and resource limitations mean that many women receive substance use treatment within mixed-gender settings. ${ }^{4}$ As such, programs augmented with web-based gender-specific materials may be able to serve as an alternative for treatment programs that would be otherwise unable to provide gender-specific treatment.

The gender-specific modules developed by Sugarman et al. comprised largely psychoeducational material derived from a group therapy format. ${ }^{1}$ The modules included in the webbased program covered the key aspects of gender-specific treatment-trauma and co-occurring psychiatric comorbidities, sexual abuse, parenting/caretaking, family violence and sexuality, among others. Satisfaction with the intervention was high and all components were highly rated as acceptable across a range of levels of care (inpatient, outpatient, and mixed) and age groups. That these modules were acceptable and feasible is an important foundation for further development of interventions in this space.

The study, however, was a pilot and, therefore, caution is needed when interpreting results and generalizations should be limited. One important limitation was that the women were mainly white and relatively well educated. This point needs to be carefully considered in terms of what these results might mean in a broader context. One issue that requires careful consideration is the varying levels of literacy, including digital literacy. The complexities of substance use disorders and its treatment extend beyond substance use history and the role of psychiatric comorbidity, and important social determinants of substance use should not be dismissed. The largely homogeneous sample does not invalidate the findings but must be considered in any broader trial or replication by anyone wishing to expand on these findings. Indeed, this is the very point of pilot studies and underscores why the publication of well-designed pilot studies is important, as it enables others to build on and learn from the preliminary work. ${ }^{5}$

Finally, it is important to remember that a women-only environment will be necessary irrespective of the treatment model. Women-only services often provide the only opportunity for women to remain with their children while receiving residential treatment, or to continue to have visit access with their children throughout treatment, which is usually essential for women working toward having custody of their child restored. ${ }^{6}$ Women-only services can also provide refuge for women with substance use disorders who are escaping intimate partner violence, or for those women with sexual abuse histories where therapeutic work involving male participants or providers may be prohibitive or damaging. These aspects of care can never be replaced with online content. $^{7}$

\section{References}

1. Sugarman DE, Meyer LE, Reilly ME, et al. Feasibility and acceptability of a web-based, gender-specific intervention for women with substance use disorders. J Womens Health 2020;29:636-646.

2. Boumparis N, Karyotaki E, Schaub MP, et al. Internet interventions for adult illicit substance users: A meta-analysis. Addiction 2017;112:1521-1532.

3. Devries KM, Child JC, Bacchus LJ, et al. Intimate partner violence victimization and alcohol consumption in 
women: A systematic review and meta analysis Addiction 2014;109:379-391.

4. McHugh RK, Votaw VR, Sugarman DE, et al. Sex and gender differences in substance use disorders. Clin Psychol Rev 2018;66:12-23.

5. Thabane L, Ma J, Chu R, et al. A tutorial on pilot studies: The what, why and how. BMC Med Res Methodol 2010; $10: 1$.

6. Fowler C, Rossiter C, Sherwood J, et al. New understandings of mothering: Mothers in an abstinence-based drug treatment program. Int J Mental Health Addict 2015;13:173-184.

7. Grella CE. From generic to gender-responsive treatment: Changes in social policies, treatment services, and outcomes of women in substance abuse treatment. J Psychoactive Drugs 2008;40 (Suppl. 5):327-343.

Address correspondence to:

Carolyn A. Day, PhD Discipline of Addiction Medicine The Sydney Central Clinical School (C39) Faculty of Health and Medicine University of Sydney Sydney, NSW 2006

Australia

E-mail: carolyn.day@sydney.edu.au 